\title{
Aids, Política e Sexualidade: refletindo sobre as respostas governamentais à Aids na África do Sul e no Brasil
}

| 'Gustavo Gomes da Costa Santos |

R esumo: Este artigo é uma tentativa de refletir sobre as respostas governamentais à epidemia de Aids a partir de dois casos contraditórios: Brasil e África do Sul. A partir do exame das trajetórias da epidemia em ambos os países e da ampla literatura escrita sobre o tema, busca-se entender o porquê de ações governamentais tão díspares em países que são, do ponto de vista socioeconômico, relativamente semelhantes. A hipótese aqui sustentada é que as inter-relações entre instituições políticas e processos mais amplos de construção da identidade nacional podem explicar as distintas respostas governamentais e iluminar a complexa relação entre Aids, sexualidade, raça e identidade nacional no Brasil e na África do Sul.

> Palavras-chave: Política de Aids; África do Sul; Brasil; instituições políticas; identidade nacional. 


\section{Introdução}

A expansão daSíndrome da I munodeficiência Adquirida (conhecida pela sua sigla em inglês - Aids) representa hoje, no chamado "mundo em desenvolvimento", um grande problema médico, político, social eeconômico (BO O N E; BAT SELL, 2001). Embora descoberta no início da década de 80, a Aids ainda hoje expira diversos cuidados não só em vista do não-descobrimento de sua cura, mas também pelo drama social que inflige a diversas populações. U ma marca importante desta epidemia, em relação a outras doenças, reside no fato de a Aids englobar diversas dimensões - cultural, social, política, médica, econômica -,0 que dificulta a compreensão da sua dinâmica, mas, com isso, instiga diversos pesquisadores e acadêmicos em geral a tentar apreender sua complexidade (GALVÃO, 2000).

0 presente texto é uma tentativa de refletir sobre as respostas governamentais à epidemia de H IV/Aids a partir de dois casos contraditórios. Embora do ponto de vista político esocioeconômico África do Sul eB rasil se assemel hem (sociedades multiétnicas, pertencentes ao quese convencionou chamar "democracias da terceira onda" (G AU RI; LIEBERM AN , 2004) e economias "emergentes" com altosgraus de desigualdade de renda), no tocante à epidemia de Aids, ambos os países constituem exemplos discrepantes amplamentereferidos na literatura especializada. Se por um lado, o Brasil constitui um caso de relativo "sucesso" na gestão da epidemia, por outro, a África do Sul é sempre citada com exemplo de "fracasso", principalmente quando se observa a dimensão al armante que a epidemia tomou, com quaseum terço da população adulta infectada pela doença (PEM BREY, 2007).

A partir da ampla literatura escrita sobre o tema, tanto sobre o caso brasileiro como sobre o sul-africano, buscar-se-á entender as especificidades que a epidemia de Aids tomou em cada contexto e, a partir das respostas governamentais à doença, refletir sobre as complexas, mas não menos importantes, relações entre cultura, política e sexual idade. Para tanto, primei ramente será feito um resgate da trajetória da doença na África do Sul e no Brasil. Posteriormente, serão sal ientadas as princi pais diferenças/similitudes entre ambos os casos. Por fim, a partir dos dados apresentados, tentar-se-á identificar as variáveis que são rel evantes para entender o porquê de respostas governamentais tão distintas em sociedades aparentemente tão parecidas. 


\section{Resgatando o histórico da epidemia: as trajetórias da Aids no Brasil e na África do Sul}

A epidemia de Aids, por sua complexidade e por influenciar diversos aspectos da vida social, tem ganhado contornos bem específicos em cada contexto no qual se disseminou. Assim, compreender o histórico e os desenvolvimentos da epidemia nos distintos contextos nacionais éde suma importância para apreender a dinâmica da doença. Para tanto, busca-se resgatar, de forma sucinta, os principais eventos, iniciativas eações de setores da soci edad e civil e principalmente dos órgãos estatais, com vistas a lidar com as problemáticas oriundas da contaminação pelo vírus H IV.

No Brasil, embora a mídia já produzisse diversas matérias sobre certo "mal" que atacava especial mente homossexuais nos EU A em 1981 e 1982, os primeiros casos deAids só foram reportados em São Paulo no ano seguinte. Conhecida então como "peste gay" ou "câncer gay", a doença trouxe consigo diversos preconceitos em relação à homossexualidade e a pessoas com comportamentos sexualmente "desviantes" ou "promíscuos" (GALV ÃO , 2000). D ada esta vinculação inicial entre homossexualidadeeAids, diversos ativistas homossexuais tiveram papel importante nas primeirasiniciativas de combateà doença. G rupos do então nascentemovimento homossexual (M acRAE, 1990) foram responsáveis pela primeira articulação da sociedade civil com órgãos de saúde para produzir uma resposta governamental à Aids. Já em 1983, a Secretaria de Saúde do Estado de São Paulo criou um programa de combate à Aids que previa, dentre várias medidas, a notificação compulsória dos casos, a criação de um serviço telefônico de aconsel hamento e a participação da sociedade no combate à doença (G ALVÃO, 2000).

0 processo de redemocratização em curso e a eleição dos primeiros governos estaduais por voto direto foram de suma importância para entender a precocidade das respostas governamentais à epidemia de Aids no Brasil. A presença do movimento sanitarista progressista na Secretaria deSaúde, juntamentecom a eleição deFranco M ontoro (1983-1987) para o governo do Estado de São Paulo abriram espaço para que as pressões de ativistas homossexuais fossem ouvidas e para que fossem tomadas as primeiras iniciativas governamentais de combate à Aids.

A iniciativa pioneira do Estado de São Paulo de criar um programa de Aids levou vários outros estadosa criarem seus próprios programas (até 1985, dez estados já contavam com suas próprias estruturas de combate à Aids) e, de certa forma, "forçou" o Governo Federal a tomar providências em âmbito nacional (GALVÃO, 
2000). Em 1985, o M inistério da Saúde estabeleceu as diretrizes para a criação do Programa N acional deAids(LEVI; VITÓ RIA, 2002). A partir de 1987, o Programa $\mathrm{N}$ acional deAids (PN Aids) desenvolveu ações devigilância epidemiológica, decontrole da infecção por H IV nas atividades hemoterápicas e campanhas de aconsel hamento edeincentivo do uso do preservativo como forma deevitar a contaminação por H IV. Já no seu início, o PN Aidsincorporou diversasiniciativas tomadas pelo programa de Aids paulista, dentreelaso caráter não-discriminatório de combateà doença, a garantia dos direitos dos afetados pela Aids ea importância da participação da sociedade civil nas ações governamentais (GALVÃO, 2000). Embora tenha tido diversas denominaçõeseter sido subordinado a diferentesórgãos, o PN Aids conseguiu manter uma ação mais ou menos regular e contínua durante as décadas de 80 e 90, apesar dos percalços do governo Fernando Collor (1990-1992). Em 1990, é tomada a decisão de distribuir gratuitamentemedicamentos para pessoas viven do com Aids, a exemplo do AZT eda pentamidina (GALVÃO, 2000).

0 empréstimo firmado entreo PN Aids eo Banco M undial constituiu um marco na história do combate à epidemia no Brasil. D entre as principais características, está a importância dada ao papel de entidades não-governamentais ( O N Gs, universidades, hospitais, fundações, sindicatos, grupos feministas e gays) tanto na execução dos projetos de prevenção quanto na elaboração ena avaliação dos mesmos (GALVÃO , 2000). O s recursos disponibilizados ampliaram o número de entidades não-governamentais trabalhando com prevenção de Aids (sugerindo até que 0 empréstimo do Banco M undial estaria incentivando a emergência, no campo de atuação das 0 N G s, de uma "indústria da Aids") e consolidaram a relevância desses atoresna gestão da epidemia no Brasil. Essa experiência de "sinergia" entresociedade civil eórgãos estatais acabou por se tornar referência no combate à Aids, constando de diversos manuais de "boas práticas" e de diretrizes de combateà epidemia para os governos nacionais (a exemplo de diversos documentos produzidos por agências internacionais, como o próprio Banco M undial e o U N Aids).

Em 1996, a aprovação da Lei federal no 9.313 garantiu o fornecimento gratuito de todos os medicamentos para o tratamento dos doentes de Aids (LEVI; VIT Ó RIA, 2002). Em 2001, 105 mil pacientes recebiam via Sistema Ú nico de Saúde (SUS) o que ficou conhecido como "coquetel anti-Aids", aumentando significativamente os recursos alocados para o tratamento dos doentes de Aids (mais de 200 milhões de dólares em 2001). O s altos custos do fornecimento 
gratuito do "coquetel", além de gerarem diversas críticas, colocavam em xeque a viabilidade do serviço. 0 M inistério da Saúde passou então a financiar empresas brasileiras que produziam os medicamentos pertencentes ao "coquetel", o que diminuiu em $50 \%$ os gastos com a provisão destes medicamentos aos doentes de Aids. M ais ainda, o governo brasileiro incumbiu-se de negociar com as indústrias farmacêuticas a diminuição dos preços dos medicamentos do "coquetel", garantindo reduções de até $60 \%$ em al gumas drogas. Q uando estas negociações não foram bem-sucedidas, o governo brasileiro ameaçou, por meio do licenciamento compulsório, ${ }^{1}$ quebrar as patentes, como foi o caso do medicamento $\mathrm{N}$ elfinavir em 2001. Esta ameaça acabou se concretizando em 2007, com o licenciamento compulsório do antirretroviral efavirenz, possibilitando uma economia anual de U S\$ 30 milhões (FO LH A D E SÃO PAU LO , 2007). A ação agressiva dos órgãos estatais e a intensa mobilização das entidades não-governamentais tiveram como consequência a diminuição substantiva do número de pessoas vítimas do H IV/ Aids. Ela chegou a 54,5\% em 1996-1997, exatamente no início do fornecimento gratuito do "coquetel" aos doentes de Aids (LEVI; VIT Ó RIA, 2002).

Ao se observar a trajetória da epidemia de Aids na África do Sul, nota-se uma trajetória em alguns pontos semelhantes, mas substancialmente distinta da experiência brasileira. Tal como no Brasil, os homossexuais foram o primeiro grupo atingido pela doença e em quase sua total idade eram indivíduos brancos, de classe média ou alta. D a mesma forma, as representações na mídia apontavam a Aids como a "praga gay", reforçando preconceitos contraa homossexualidade(GEVISSER, 1995). M as as semelhanças terminam por aqui. Ao contrário da atitude da militância homossexual brasileira diante da doença, na África do Sul o grupo GASA (G ay Association of South Africa), sediado em J oanesburgo, divulgou um pôster no qual afirmava que o perigo representado pela Aids era "exagerado" ("overstressed") e isolou a sucursal do grupo na Cidade do Cabo (GASA-6010) no trabalho de assistência às vítimas da doença. Em 1985, foi reportado na mídia o primeiro caso deAids em um homem negro em Soweto, que teria sido contaminado por um gay negro que supostamentefrequentava o gueto gay branco em J oan esburgo, reforçando a vinculação entre Aids e homossexualidade (GEVISSER, 1995).

As primeiras iniciativas estatais de combate à Aids partiram do então governo da minoria branca, que adotou uma postura repressiva e discriminatória, "racializando" a epidemia e vinculando-a a comportamentos sexuais "desviantes" 
(GAU RI; LIEBERM AN , 2004). As ações do governo sul-africano nesta primeira fase da epidemia foram permeadas por falta de planejamento, organização e desconectadas da realidade das pessoas vivendo com Aids. Em 1988, o governo promoveu programas de combateà Aids separados para brancosenegros, reforçando mitos existentes sobre a vinculação entre a raça e a Aids. N a comunidade branca, a Aids serviu de "motivo" para evitar a des-segregação das prai as (de acordo com a legislação do aparthe d², todosos espaços públicos eram segregados em locais "apenas para brancos" e "para não-brancos"), devido ao receio de vários brancos de serem contaminados pelo vírus "negro" da Aids. Por parte da população negra, a Aids era vista com fruto de uma grande conspiração, na qual o governo branco havia deliberadamenteimplantado o vírus H IV para evitar o movimento deliberação da maioria negra3 (GAURI; LIEBERM AN , 2004).

Com a libertação de $\mathrm{N}$ el son $\mathrm{M}$ andela e a legalização do Congresso $\mathrm{N}$ acional Africano (CN A) em 1990, iniciou-se o conturbado período de transição para a democracia que culminou nas primeiras el eições livres multirraciais realizadas em 1994 (JOH N SO N , 2005; RO SS, 1999). Em 1992, numa demonstração de unidade nacional, o C N A eo M inistério da Saúde realizaram uma conferência que resultou na criação do N ACO SA (T he N ational Aids Committee of South Africa), que propunha a organização de um programa nacional de combate à Aids. Este plano contou com a mobilização de diversos setores da sociedade civil e buscava criar um paradigma não-discriminatório de enfrentamento à epidemia. Previa também que o governo deveria desempenhar papel importante na concatenação das ações de diversos órgãos estatais. Ao tomar posse em 1994, o então presidente eleito $\mathrm{N}$ el son $\mathrm{M}$ andela apontou o programa de Aids como um dos carros-chefe do novo governo. N o entanto, apesar do posicionamento do novo governo em prol de um amplo programa de combate à Aids, diversas dificuldades abortaram as expectativas do programa desenhado pelo NACOSA. A primeira delas é que 0 programa de Aids ficou sob responsabilidade do M inistério da Saúde, que possuía funcionários públicos oriundos do governo de minoria branca ${ }^{4}$ com uma visão biomédica estreita da epidemia de Aids. 0 ministério também passou por uma grande reestruturação oriunda do processo de descentralização administrativa, que acabou por dificultar a atribuição de papéis e responsabilidades entre os diversos agentes governamentais. D eacordo com a nova constituição, as províncias ficaram responsáveis pela implementação das políticas de saúde, mas, ao mesmo tempo, 
elas se mantiveram dependentes dos recursos enviados pelo governo central, visto que os impostos são arrecadados em nível nacional e posteriormente distribuídos entre as províncias (BUTLER, 2005; SCH N EIDER; STEIN , 2001). Soma-se a isso o fato deque os recursos destinadospelo governo central às provínciassão enviados em bloco, sem uma alocação específica para setores como saúde ou educação. Com isso, os recursos destinados ao programa de Aids variam significativamente entre as províncias, comprometendo ainda maisagestão da epidemia(SCH N EIDER; STEIN , 2001). Além disso, o M inistério da Saúde possuía pouquíssimas conexões com entidades não-governamentais, dificultando ainda mais a ação governamental de combate à doença (SCH N EID ER; ST EIN , 2001).

A ausência de sinergia entre entidades da sociedade civil e os órgãos governamentais é amplamente apontada na literatura com outro fator decisivo no "fracasso" das respostas do governo sul-africano à epidemia deAids (BUT LER, 2005; SCHNEIDER; FASSIN, 2002). Embora os primeiros anos do novo governo tenham sido caracterizados por diversos experimentos de participação social na gestão de políticas públicas (C AM AY; G O RD O N , 2004), em al gumas áreas ditas "estratégicas" para o governo, a exemplo da política de combate à Aids, o CN A tomou uma postura centralizadora de gestão. Com uma longa tradição de "centralismo democrático" oriunda dos anos de militância marxista contra 0 apartheid, diversas lideranças do partido passaram a tolerar cada vez menos posturas dissidentes e críticas às políticas do governo, principalmente na política de Aids (BUTLER, 2005). Isso acabou por dificultar o diálogo e a cooperação entre setores da sociedade civil e os órgãos estatais, quando não os colocou em conflito aberto ( $O H N S O N, 2004)$. Devido a estas e outras dificuldades (como por exemplo, o ajuste estrutural do Estado sul-africano, que diminuiu consideravelmente os recursos para programas sociais), o programa de combateà Aids era caracterizado, no final de 1998, como um conjunto confuso eincoerente de esferas múltiplas e paralelas, que não conseguia concatenar ações de combate à epidemia (SCH N EID ER; STEIN , 2001).

Várias polêmicas recentes atestam o "fracasso" do governo sul-africano em produzir respostas eficazes à epidemia de Aids. U ma delas foi a produção de um musical educativo baseado no filme "Sarafina", que foi al vo da várias críticas pelo fato denão prover uma mensagem clara e profícua sobre o combateà doença, além de o governo ter sido acusado de superfaturamento na produção do material 
(GAU RI; LIEBERM AN , 2004; SCH N EIDER; STEIN , 2001). 0 utra polêmica ocorreu com a decisão do governo de promover um tratamento sul-africano revolucionário contra a Aids, baseado em medicamento (V irodene) desenvolvido numa universidade local, alvo de diversas críticas da classe médica por não ter sido adequadamente testado em humanos (SCH NEIDER; STEIN, 2001). M as a principal delas foi protagonizada pelo então presidente Thabo M beki (19992008) em 2000. N a abertura da C onferência Internacional de Aids realizada em D urban, o presidente questionou a transmissão sexual do H IV/Aids. Baseando-se em trabalhos de cientistas "dissidentes", M beki afirmou acreditar que a contaminação por HIV é resultado da pobreza e da desnutrição e não do ato sexual. Para ele, as teorias que atestam a transmissão do H IV por via sexual estão baseadas em pressupostos racistas, que vinculariam o aumento expressivo de casos de Aids na África subsaariana a uma suposta sexual idade "exacerbada, violenta e animalesca" do homem negro (PO SEH , 2006). Afora isso, o presidente questionou a eficácia do AZT e das drogas contidas no "coquetel anti-Aids" e afirmou que as pressões para o fornecimento gratuito desses medicamentos pelo governo respondiam aos interesses das indústrias multinacionais farmacêuticas. A postura de $M$ beki gerou um confronto aberto entre as organizações da sociedade civil, principalmente da C ampanha A ção pelo Tratamento (Treatment Action Campaign - CAT ) e o governo, eentre diversos governos provinciais e o governo central, pelo fornecimento do "coquetel anti-Aids" para mulheres grávidas infectadas com H IV / Aids (SCH NEIDER; FASSIN , 2002). A CAT acionou a Corte Constitucional, que proferiu uma decisão histórica em 2002, obrigando o governo a fornecer gratuitamente as drogas pertencentes ao "coquetel anti-Aids" (POSEH, 2006). A pós a decisão da Corte Constitucional eo rechaço da comunidade internacional à posição do presidente $\mathrm{M}$ beki, o governo recuou na sua decisão, prevendo o fornecimento do "coquetel anti-Aids" na tentativa de diminuir a transmissão do vírus H IV das mães para seus bebês.

Esta sequência de ações desorganizadas, a desarticulação dos diversos órgãos estatais, a falta de sinergia entre governo e sociedade civil, juntamente com a postura "negacionista" do presidente M beki, tiveram como consequência nefasta 0 aumento alarmante do número de pessoasinfectadas com o H IV /Aids. I sso garantiu a África do Sul o triste recorde de país com maior número de infectados, que chega, numa das diversas estimativas, a 5 milhões e meio de pessoas 
(aproximadamente um terço da população adulta) vivendo com o vírus H IV eao assustador número de mil mortes por dia devido à Aids (PEM BREY, 2007).

O sucinto histórico da epidemia de Aids no Brasil ena África do Sul exposto até aqui buscou contextualizar o problema e resgatar fatores que podem ser explicativos para respostas governamentais tão díspares em países relativamente semel hantes do ponto de vista socioeconômico. $\mathrm{N}$ a próxima seção será feita uma tentativa de resgatar tais fatores na ampla literatura escrita sobre o tema, com 0 intuito de entender quais desses fatores são preponderantes para explicar as diferentes respostas governamentais em ambos os países.

\section{Aids, sexualidade, raça e identidade nacional}

O s programas governamentais de combate à Aids no Brasil e na África do Sul foram objeto de diversos trabalhos que analisam tanto o "sucesso" do primeiro quanto o "fracasso" do segundo. Embora os diagnósticos apontem diversas variáveis explicativas para ambos os casos, al gumas delas, referentes ao sistema político de ambos os países (sistema de governo, arcabouço burocrático, participação ou não da sociedade civil, entre outras), foram recorrentemente citadas.

Para refletir sobre estas experiências, tomamos por base a literatura acima citada e o importante trabal ho deV. G auri eE. Lieberman (2004), que se empenharam especificamente em analisar as respostas governamentais de combate à Aids no Brasil e na África do Sul. N este trabal ho, os autores realizam o exame de diversas variáveis apontadas na literatura e verificaram a relevância delas para compreender os dois casos anal isados. Fatores como organização da burocracia estatal responsável pela política de Aids, centralização administrativa, existência de uma sociedade civil atuante na área e capacidade de ação estatal, entre outras, foram levadas em conta na análise. 0 s autores sustentaram que dois fatores explicariam as respostas divergentes em relação à Aids: a descentralização das instituições políticas preexistentes ea força da comunidade política nacional. G auri eLieberman (2004) observaram que a descentralização do aparato estatal no Brasil, em virtude de sua organização federal, foi fundamental para uma resposta relativamente precoce e eficaz no combate à doença. Para eles, as instituições políticas estabeleceriam 0 espaço político (policy surface area) disponível para a ação dos empreendedores de políticas públicas (policy entrepreneurship). Esse espaço aumentaria quanto maior fosse o número de pontos autônomos de tomada de decisão de políticas 
públicas. Em contextos institucionais descentralizados, tais empreendedores poderiam realizar rápidos progressos no que concerne à implementação de políticas públicas no nível subnacional, criando com isso parâmetros e pressão política de baixo para cima. Este seria o caso do Estado de São Paulo, que criou um programa de combate à Aids já em 1983, servindo de exemplo para outros estados e para o G overno Federal (GALV ÃO , 2000). N o caso específico da Aids, que esteve inicial mente vinculada a práticas sexuais "desviantes", constituindo para muitos políticos um "bicho-papão político" (political boogeyman), a descentralização criou mais oportunidades para que ações fossem tomadas em nível local, pressionando os níveis mais altos da administração a tomarem consciência da dimensão do problema e atuarem de forma a resolver a questão nacionalmente (GAURI; LIEBERM AN , 2004).

O utro aspecto apontado pelos autores foi o caráter fragmentado do poder político no Brasil. Além do federalismo, os autores apontaram a fragmentação do sistema partidário (no qual, no período de 1985 a 2004, nenhum partido obteve a maioria das cadeiras no Legislativo) e a existência de diversas esferas de poder (por exemplo, a separação dos poderes ea importância do judiciário) como aspectos do sistema político brasileiro que ampliaram as oportunidades para implementar a política de Aids no Brasil.

Ao observamos o sistema político sul-africano, nota-se um contexto político radicalmentedistinto. 0 Estado sul-africano herdado do governo da minoria branca é extremamente centralizado e ainda continua assim em grande medida, mesmo com as iniciativas de descentralização previstas pela Constituição promulgada em 1996 (BUTLER, 2003). Ademais, o sistema de governo é um híbrido de presidencialismo e parlamentarismo (o presidente é eleito pelo parlamento, mas possuí poderes equivalentes aos presidentes em sistemas presidencialistas) com um partido dominante (o CN A), que controla mais de $60 \%$ dos assentos do parlamento e a maioria dos governos provinciais (BUTLER, 2003; GAURI; LIEBERM AN , 2004). Exemplo dos efeitos desta centralização foi a repreensão, por partedo governo central em 2002, deiniciativas como a do governo da província de K wazulu-N atal, dedisponibilizar o "coquetel anti-Aids" para mulheres grávidas nos seus serviços de saúde, quando da polêmica lançada pelo presidente M beki sobre a real eficácia desses medicamentos (GAU RI; LIEBERM AN , 2004). Como dito anteriormente, a ação dos governos provinciais é limitada ainda pela 
dependência dos recursos repassados pelo governo nacional, responsável pela arrecadação de impostos. V isto quea maioria das províncias está sob o controle do CN A, a pressão para seguir as orientações políticas nacionais é dupla, tanto por parte do Executivo quanto da liderança do partido. Esta, por outro lado, éadepta da prática do "centralismo democrático", no qual as decisões dasinstâncias superiores do partido devem ser seguidas à risca pelas instâncias inferiores, sob o risco de diversas formas de sanções (BU T LER, 2005; G AU RI; LIEBERM AN , 2004).

0 outro conceito apontado pelos autores como explicativo das respostas governamentais distintas de combateà Aids no Brasil ena África do Sul éa força da comunidade política nacional (CPN). Formulada como "uma definição patrocinada pelo Estado de quem está ou não incluído na 'nação' e de que forma" (GAURI; LIEBERM AN , 2004, p. 12), a CPN teria grande influência nos níveis gerais de apoio às políticas de combate à Aids por meio do impacto que ela promoveria nas percepções dos riscos e das responsabilidades, assim como nos cálculos em relação aos benefícios da ação de combate à epidemia" (GAU RI; LIEBERM AN , 2004, p. 12). Em outras palavras, a força da CPN seria medida pela intensidade dos vínculos de pertencimentos individuais a um determinado grupo de cidadãos que são aten didos pelos serviços do Estado. Para os autores, a África do Sul, por todo seu histórico de segregação racial e de conflitos étnicos sangrentos, teria uma CPN fraca. Para eles, particularmente as clivagens étnicas constituiriam um importante impedimento para a formação de um sentimento forte de pertencimento a uma comunidade, que, por sua vez, impediria a formulação eimplantação de políticas públicas (GAURI; LIEBERM AN , 2004). A variável "força da CPN" também teria importância para compreender especificamente a política de Aids.

Como salientado anteriormente, a epidemia deAidsfoi "racializada" desdeseu início, com brancos acusando negros de disseminarem a doença enegros acusando brancos de implantarem conscientemente o vírus, visando a dizimar a população negra, além de os homossexuais serem alvo de várias acusações de terem trazido o vírus H IV para o país. Já no Brasil, a Aidsteria sido identificada como um problema nacional, passível de atacar tanto heterossexuais como homossexuais, da mesma forma que brancos e negros (GAU RI; LIEBERM AN , 2004).

É com relação à variável "força da CPN " que gostaríamos de pontuar al gumas questões que consideramos relevantes para melhor compreen der as distintas respostas 
governamentaisno combateà Aids. É importante salientar que, tal como formulado no texto, o conceito de CPN é definido de forma dúbia e imprecisa, em al gumas partes do texto significando uma definição de nação enquanto sentimento de pertencimento e de solidariedade e em outras significando meramente a soma dos indivíduos que são legalmente reconhecidos como cidadãos de um determinado país. Além disso, os indicadores da suposta "força" ou "fraqueza" da CPN são limitados, visto que os autores apontam dados esparsos do World ValueSurvey para sustentarem sua hipótese. M esmo assim, eles própriosjá indicam em várias passagens do texto o que seria, a nosso ver, a questão mais relevante para entender as respostas governamentais tão díspares à epidemia de Aids: a complexa relação entre Aids, sexualidade, raça e identidade nacional no Brasil e na África do Sul.

A Aids, da mesma forma que outras doenças sexualmente transmissíveis, a exemplo da sífilis, traz consigo uma grande carga de estigma e preconceito, e o combate a elas envolve mudanças de hábitos e práticas fortemente enraizadas nas crenças e val ores culturais de uma determinada sociedade, dificultando com isso a ação dos poderes públicos. Ao ol harmos para o caso brasileiro, já podemos encontrar na sua história um importante exemplo de "sucesso" de políticas concernentes à sexualidade. Ao analisar a política de combateàs doenças venéreas (em especial a sífilis) no final do século XIX e princípio do século XX, Carrara (1994) observou como o Brasil aplicou uma política relativamente ampla de profilaxia e de educação sexual com vistas a controlar a expansão da doença. Ao contrário dos países europeus, que aplicaram a regulação ou a proibição da prostituição como forma de combate às doenças venéreas, no Brasil, os poderes públicos adotaram uma postura de promover a educação sexual da população masculina, visando a combater o preconceito, visto como obstáculo à erradicação da doença emodificar práticas sexuai s existentes(CARRARA, 1996). M aisainda, o G overno Federal, buscando defender a "nação", disponibilizou uma estrutura relativamente ampla de clínicas para tratamento da doença (os dispensários antivenéreos), além de criar um serviço de "visitadoras", que buscavam "dissuadir" as prostitutas a tratarem as doenças venéreas. Ao invés de adotar um discurso puramente moralista e de repressão à prostituição, o governo brasileiro tomou uma postura "pragmática", buscando mudanças do comportamento sexual masculino e provendo os meios para a cura da doença, postura essa seguida posteriormente por países europeus (CARRARA, 1994 e 1996). 
Jáno caso sul-africano, ainda nos primórdios da colonização inglesa, as políticas de saúde sem pre estiveram relacionadas aos discursos e práticas racistas do governo colonial branco em relação aos "nativos". Em vários momentos, as metáforas raciais de "pureza" "degeneração" influenciaram as interven ções sanitárias quetentavam "gerir" o "perigo" oriundo de localidades superpovoadas por "nativos" que começavam a surgir nas principais cidades sul-africanas no princípio do século XX. Ao analisar a "síndrome sanitária" presente no combate do governo colonial inglês à peste bubônica na Colônia do C abo, Swanson (1977) aponta que uma importante linha de ação do Estado consistiu em separar e isolar a população branca da horda de "nativos" (africanos, coloreds e indianos), vista como principal "vetor" da disseminação da doença na colônia. Foi neste contexto que se iniciou a prática de "deslocamento compul sório" da população "nativa" das zonas centrais das grandes cidades para áreas especificamente designadas nas periferias dessas cidades. Esta prática foi recorrente durante o período do apartheid (1948-1994), quealegava motivos "de saúde pública" para expulsar e deslocar populaçõesfaveladas das periferias das principais cidades sul-africanas (POSEL, 2006). Estas favelas eram caracterizadas como locais "catal isadores de uma desenfreada promiscuidade edecadênciamoral" oriundos do processo de "destribalização" dos "nativos" (POSEL, 2006). Estes eram vistos como detentores de uma sexualidade supostamente "animalesca e promíscua" erepresentavam um "perigo" para a população civilizada branca. Por sinal, até o fim do apartheid, a sexualidade era, ao contrário do Brasil, objeto de extrema regulação por parte do Estado, que proibia a prática sexual entre pessoas de grupos raciais distintos ${ }^{6}$ (M O UT IN H O , 2004), a exposição ea discussão pública de questões relacionadas ao sexo (PO SEL, 2006) e condenava a prática da sodomia tanto em âmbito público como privado (GEVISSER, 1995).

$N$ este ponto é importante resgatar a controvérsia levantada pelo presidente M beki em relação à contaminação via sexual por H IV /Aids. Segundo Posel (2006), 0 presidente negaria a vinculação entre Aids e sexo de duas formas: a primeira, afirmando que a Aids está vinculada à pobreza e à desnutrição e não ao sexo; e a segunda, recusando tal vinculação, que, severdadeira, para ele (em vista da dimensão do problema) teria consequências intoleráveis. Para M beki, afirmar que a Aids é transmitida por via sexual éreiterar argumentos racistas, enraizados nos esterétipos sobre "a voraz eviolenta sexualidade do homem negro" (PO SEL, 2006, p. 53). Ao analisar relações inter-raciaisno Brasil enaÁfrica do Sul, M outinho (2004) aponta 
para a importância que o desejo erótico inter-racial teve como "constituidor da nação", mesmo que de formas radicalmente distintas. No Brasil, o casal formado pelo "português libidinoso" e a "mulata" de Gilberto Freyre foi saudado como a "realização do erotismo que une 'raça', nacionalidades e classes distintas, cerzindo as alteridades e corporificando uma nação" (M O UTIN H O , 2004, p. 425). Já na África do Sul, a ameaça representada pelo desejo do "homem negro" pela "mulher branca" expressa o sentimento de destruição do volk africâner, destruição essa que, "ao 'demonizar' as alteridades raciais, al imentava fronteiras, desenvolvendo um certo sentimento de pertencimento e, também neste caso, de nação" (M OUTIN H O, 2004, p. 425). Ao invés de pensar numa "comunidade política nacional" "fraca" ou "forte(GAU RI; LIEBERM AN , 2004), éimportanterefletir como cada comunidade política constrói sua ideia de nação ea forma como, no caso específico do Brasil eda África do Sul, a "raça" e a sexualidade se inter-relacionam neste processo.

A recusa do presidente $M$ beki em reconhecer a vinculação entre Aids e prática sexual demonstra como as representações essencial izantes eestigmatizantes de raça, sexualidade e doença (principalmente referentes à sexualidade e ao corpo do "homem negro") ainda permeiam o imaginário social da África do Sul pós-aparthe d7 (POSEL, 2006), dificultando uma resposta governamental mais agressiva à epidemia de Aids. Longe de retratar o Brasil como um paraíso de liberação sexual e tampouco uma "democracia racial", não se pode negar que o processo de construção da identidade nacional brasileira propiciou um contexto social mais favorável, em relação à África do Sul, a uma resposta eficaz à epidemia de Aids. Como afirmaC arrara (1996), a própria política antivenérea tevegrandeimportância na expansão da ação do Estado brasileiro e no processo de construção nacional (nation-building). Portanto, sustentamos a hipótese de que as intricadas relações entre as instituições políticas e a construção da ideia de nação no Brasil ena África do Sul ajudam a compreender de forma mais acurada as respostas tão distintas ao problema representado pela epidemia deH IV /Aids em contextos sociais, do ponto de vista socioeconômico, relativamente semelhantes.

\section{Considerações finais}

Ao analisar a política de Aids, pode-se refletir sobre al gumas questões relevantes para as ciências sociais em geral ea ciência política em particular. A primeira delas diz respeito à importância de analisar as dinâmicas específicas que a epidemia de 
Aids apresentou nos diversos contextos nacionais. Ao invés de aplicar rigidamente o manual de "boas práticas" e as experiências de "sucesso" de outros países, é importante levar em conta, na elaboração e implementação de políticas públicas, as especificidades da epidemia de Aids em cada sociedade.

O utra questão diz respeito a análises das políticas de Aids que levam em conta apenas variáveisinstitucionais equeenfatizam uma suposta "racionalidade" dosatores envolvidos na elaboração e implementação dessas políticas. Como tentamos demonstrar ao longo do texto, as instituições políticas são uma variável-chave na compreensão dos rumostomados pelas distintas políticas de combateàAids. C ontudo, essas instituições estão local izadas em contextos nacionais específicos, são moldadas por processos mais amplos de construção da nação (nation-building) eosatores nelas envol vidos estão imbuídos de valores e práticas concernentes às culturas específicas. $\mathrm{N}$ este ponto é importante salientar o vínculo intrínseco entre cultura e política. No caso específico daAids, pode-seobservar como osvaloreseas representaçõesculturais influenciaram decididamente as respostas das instituições políticas à expansão da doença, ecomo taisvalores erepresentaçõesforam em grande partefrutos deamplos processos políticos de construção da nação, a exemplo da ideologia de "demonização" do corpo negro promovida pela minoria branca durante o aparthed.

$M$ ais ainda, é importante frisar o papel que a sexualidade teve na constituição do ideal de nação em ambos os países. N o Brasil, por um lado, isso se deu por meio da exaltação do "encontro" entre as "raças", representado pelo casal "homem branco" e "mulher mestiça" que unia "raça', nacionalidades e classes distintas, cerzindo as alteridades e corporificando uma nação" (M O UTIN H O , 2004, p. 425). N a África do Sul, por outro lado, a negação e a "demonização" do desejo sexual do "homem negro" pela "mulher branca" foram fundamentais para sedimentar a fronteira intransponível entre a minoria branca e a maioria negra eo sentimento de pertencimento ao volk africâner, constituindo um ideal de nação segregado racialmente, que permanece em grande medida até hoje.

\section{R eferências}

BO O N E, C.; BAT SELL, J. Politics and Aids in Africa: Research Agendas in Political Scienceand International Relations. Africa Today, v. 48, n. 2, p. 3-33, 2001.

BUT LER, A. South Africa's H IV/Aids policy, 1994-2004: how can it be explained? African Affairs, v. 104, n. 417, p. 591-614, 2005. 
CAM AY, P.; GO RD O N , A. Evolving democratic governancein South Africa. Johannesburg: Core, 2004. 480 p.

CARRARA, S. A Aidsea história das doençasvenéreas no Brasil. In: PARKER et al. (org.). A Aids no Brasil (1982-1992). Rio deJ aneiro: Relume D umará, 1994. 360p.

CARRARA, S. Tributo a Vênus a luta contra a śfilis no Brasil, da passagem do século aos anos 40. Rio deJ aneiro: Fiocruz, 1996. 339p.

FO LH A D E SÃO PAU LO . Patentequebrada: 0 Brasil tem o direito delicenciar drogaanti-Aidse boas razões para fazêlo; isso não implica que decisão seja sem custos. São Paulo, 05. mai.2007, Editorial.

GALVÃo, J. Aidsno Brasil: a agenda de construção de uma epidemia. São Paulo: Editora34, 2000. $256 \mathrm{p}$.

GAU RI, V.; LIEBERM AN , E. Aids and the State: The politics of government responses to the epidemic in Brazil and South Africa. In: ANNUAL MEETINGS OF THE AMERICAN PO LITICAL SCIEN CE ASSO CIATIO N . Chicago, 2004.52 p.

GEVISSER, M . A different fight for freedom: a history of South African lesbian and gay organization from the 1950sto the 1990s. In: GEVISSER, M .; CAM ERO N , E. (org.). D efiant desire gay and lesbian lives in South Africa. N ew York: Routledge, 1995. p. 14-86.

JO H N SO N , K. ThePolitics of Aids policy development and implementation in post-apartheid South Africa. Africa Today, v. 51, n. 2, p. 107-128, 2004.

JO H N SO N , R. W. H istoria deSudáfrica: el primer hombre, laúltimanación. Barcelona: Random H ouse M ondadori, 2005. 421 p.

LEVI, G . C.; VIT Ó RIA, M . A. A. Fighting against Aids: the Brazilian experience. Aids, v. 16, n. 18, p. 2.373-2.383, 2002.

M ACRAE, E. A construção da igualdade: identidade sexual e política no Brasil da "A bertura". Campinas: Ed. Unicamp, 1990. 321p.

M O UTIN H O , L. Razão, "cor" edesejo: uma análise comparativa sobre rel acionamentos afetivosexuais "inter-raciais" no Brasil ena África do Sul. São Paulo: Ed. Unesp, 2004. 452p.

PEM BREY, G. HIV \& Aids in South Africa. Disponível em: «ttp://www.avert.org/ aidssouthafrica.htm>. Acesso em: 02.abr.2007.

POSEL, D . A controvérsia sobreaAidsnaÁfrica do Sul: marcas da política devidaemorteno pósapartheid. Afro-Ásia, n. 34, p. 39-66, 2006.

RO BIN S, S. Sexual rightsand sexual cultures: reflectionson "theZumaaffair" and "new masculinities" in thenew South Africa. H orizontes Antropológi cos, ano 12, n. 26, p. 149-183, 2006.

ROSS, R. A concisehi story of South Africa. C ambridge: CambridgeU niversity Press, 1999. 219 p. 
SCH N EID ER, H .; STEIN , J. I mplementing Aids policy in post-apartheid South Africa. Social

Science and M edicine, v. 52, p. 723-731, 2001.

SCH NEID ER, H .;eFASSIN , D . D enial and defiance: a socio-political analysis of Aidsin South Africa. Aids, v. 16, suppl. 4, S45-S51, 2002.

SWAN SO N , M . The sanitation syndrome: bubonic plague and urban native policy in the Cape Colony 1900-1909. Journal of African H istory, XVIII, n. 3, p. 387-410, 1977.

\section{Notas}

${ }^{1} 0$ Licenciamento compulsório está previsto no artigo 71 da Lei no 9.279/96, que possibilita a quebra de patentes de medicamentos em casos de "emergências sanitárias ou de interesse público" (FO LH A DE SÃO PAU LO , 2007).

${ }^{2}$ Reservation of SeparateAmenities Act de 1953

${ }^{3}$ Entrea população negra, a Aids tinha o apelido de "Afrikaner Invention to D epriveus of Sex" (G AU RI; LIEBERM AN , 2004).

${ }^{4} \mathrm{U} \mathrm{m}$ dos termos acordados no processo de transição democrática foi a manutenção da estabilidade no emprego, por cinco anos, dos funcionários públicos do regimeda minoria branca (J O H N SO N , 2004).

${ }^{5}$ Baseado na peça de M bongeni $\mathrm{N}$ gema e estrelado por W hoopi G oldberg, o filme trata da história de uma professora que ensina seus jovens alunos negros a lutarem por seus direitos na África do Sul sob o regime do apartheid. 0 filme foi lançado em 1993 e dirigido por Darrel Roodt.

6 Prohibition of M ixed M arriage Act de 1949 el mmorality Act de 1950.

${ }^{7} 0$ utro importante trabalho que aponta tal persistência é a análise do processo oriundo da acusação de estupro contra o deputado do CN A Jacob Zuma em 2006 (RO BIN S, 2006). 


\section{Abstract}

Aids, Politicsand Sexuality: analyzing
government responses to Aidsin Brazil and South Africa

This paper attempts to analyze the governmental responses to Aids epidemic in two conflicting cases: Brazil and South Africa. D rawing on the examination of Aids epidemic's trajectories in both countries and the extensive literature about that thematic, we try to comprehend the reason for such diversified governmental responses to those similar sociopolitical contexts. The paper supports that the inter-relations between political institution and wider processes of nation-building can explain such different governmental responses to Aids and illuminate the complex relationship between Aids, sexuality, race and national identity in Brazil and South Africa.

\footnotetext{
> Key words: Aids policy, Brazil, South Africa, political institutions, national identity.
} 